\title{
Repeatability and interobserver reproducibility of Artemis-2 high-frequency ultrasound in determination of human corneal thickness
}

This article was published in the following Dove Press journal:

Clinical Ophthalmology

18 May 2012

Number of times this article has been viewed

\author{
Kelechi C Ogbuehi \\ Uchechukwu L Osuagwu \\ Outpatient Clinic, Department \\ of Optometry, King Saud University, \\ Riyadh, Kingdom of Saudi Arabia
}

Background: The purpose of this study was to assess the repeatability and limits of agreement of corneal thickness values measured by a high-frequency ultrasound (Artemis-2), hand-held ultrasound pachymeter (DGH-500) and a specular microscope (SP-3000P).

Methods: Central corneal thickness (CCT) was analyzed in this prospective randomized study that included 32 patients (18 men and 14 women) aged 21-24 years. Measurements were obtained in two sessions, one week apart, by two examiners with three devices in a randomized order. Nine measurements were taken (three with each device) on one randomly selected eye of each patient in each measurement session. The coefficient of repeatability and interobserver reproducibility for the values of each method were calculated. The limits of agreement between techniques were also evaluated.

Results: There were no significant differences in CCT values between sessions for each of the three devices $(P>0.05)$. The repeatability coefficients for the Artemis-2 $( \pm 8 \mu \mathrm{m} / \pm 9 \mu \mathrm{m})$ were superior to those of the SP-3000P $( \pm 9 \mu \mathrm{m} / \pm 11 \mu \mathrm{m})$ and DGH $500( \pm 12 \mu \mathrm{m} / \pm 12 \mu \mathrm{m})$ in session 1/session 2 respectively, while the interobserver reproducibility index (differences between session 1 and session 2) was superior for the SP-3000P ( $\pm 17 \mu \mathrm{m})$ with respect to DHG-500 $( \pm 29 \mu \mathrm{m})$ and the Artemis-2 $( \pm 31 \mu \mathrm{m})$. In session 1 and session 2 , the limits of agreement between the techniques were $35 \mu \mathrm{m}$ to $-31 \mu \mathrm{m}$ and 34 to $-20 \mu \mathrm{m}$, respectively, for DGH-500 versus Artemis-2, $73 \mu \mathrm{m}$ to $3 \mu \mathrm{m}$ and $60 \mu \mathrm{m}$ to $9 \mu \mathrm{m}$ for Artemis- 2 versus SP-3000P, and $58 \mu \mathrm{m}$ to $22 \mu \mathrm{m}$ and $72 \mu \mathrm{m}$ to $10 \mu \mathrm{m}$ for DGH-500 versus SP-3000P comparisons. The DGH-500 and Artemis-2 gave similar values $(P>0.05)$ in both sessions, but both (Artemis-2 and DGH-500) values were significantly greater than that of the SP-3000P $(P<0.05)$ in both sessions.

Conclusion: Repeatability was comparably good for the three techniques. However, interobserver reproducibility was approximately twice as good with the SP-3000P compared with the other two devices. The Artemis-2 CCT values consistently agreed with the DGH-500 and less so with the SP-3000P. The Artemis-2 provided CCT values that were, on average, $38 \mu \mathrm{m}$ and $34 \mu \mathrm{m}$ greater than that of the SP-3000P in session 1 and session 2, respectively.

Keywords: cornea thickness, Artemis-2 ultrasound, hand-held ultrasound, SP-3000P noncontact specular microscopy, reproducibility

\section{Introduction}

Assessment of central corneal thickness (CCT) has assumed considerable clinical importance in relation to the planning of corneal refractive surgery, ${ }^{1,2}$ management after refractive surgery, ${ }^{3}$ diagnosis and monitoring of corneal ectasia such as keratoconus and Fuchs' dystrophy, ${ }^{4,5}$ and in the evaluation of corneal health in patients with contact lenses. ${ }^{6}$ It has also been shown to be an independent risk factor 
for the development of primary open angle glaucoma, ${ }^{7}$ and to have an influence on intraocular pressure measurements obtained by Goldmann applanation tonometry. ${ }^{8}$ Variations in CCT change the resistance of the cornea to indentation. Whereas a thinner cornea may require less force to flex, leading to underestimation of the true intraocular pressure, a thicker cornea may require a greater force to bend it, thus giving an artifactually high intraocular pressure reading. ${ }^{9}$ This could lead to a misclassification in the diagnosis of patients with ocular hypertension or glaucoma. Accurate determination of corneal thickness is also essential in selection of the right candidates for cornea refractive surgery, because its value helps to determine the feasibility of surgery, the best type of surgery, and the surgical plan. ${ }^{10}$ The most commonly used technique for measuring corneal thickness is hand-held ultrasound pachymetry, a technique that has long been considered the traditional "gold standard" of measurement but which is currently being challenged, as newer, more precise devices are introduced. Inherent disadvantages of ultrasound pachymetry include the fact that the eye under evaluation must be anesthetized, a probe must contact the corneal surface directly, and the results obtained may be adversely affected by fluctuations in tissue hydration..$^{11,12}$ Accurate measurement of CCT with the hand-held ultrasound pachymeter relies on placement of the probe as close as possible to the central cornea. Higher values will be obtained if the probe is not placed at 90 degrees to the corneal surface or if placed slightly off center. ${ }^{3}$ With hand-held ultrasound pachymetry, the same place on the cornea is not measured on every occasion, and because the cornea varies in thickness according to location, this adds to some error. Recently, various methods have been used to measure CCT, including ultrasound biomicroscopy, ${ }^{13}$ noncontact specular microscopy (SP-3000P),${ }^{14}$ slit scanning (Orbscan), ${ }^{11,15}$ optical pachymetry, ${ }^{11}$ coherence interferometry, ${ }^{16}$ high-frequency ultrasound (Artemis-2), ${ }^{17}$ Scheimpflug imaging (Pentacam), ${ }^{18}$ and optical coherence tomography (Visante). ${ }^{19}$ The basic operational theory of these instruments is the same, ie, the reflection of light or ultrasound from the anterior and posterior corneal surfaces allows the instrument to assess the thickness of the cornea at that location. The Topcon SP-3000P noncontact specular microscope (Topcon Corporation, Tokyo, Japan) is an upgraded version of the SP-2000P which includes a function to evaluate the endothelial layer simultaneous with assessment of corneal thickness. Focusing on the endothelium, this instrument provides specular images and measures focal distance, from which the corneal thickness can be calculated. With an enhanced image memory, five images for each eye can be taken simultaneously, in contrast with three using the older version.

The hand-held ultrasound pachymeter DGH-500 (DGH Technology Inc, Exon, PA), operating at a frequency of $50 \mathrm{mHz}$, emits short acoustic pulses and detects reflections from the anterior and posterior surfaces of the cornea. Corneal thickness is then calculated from the measured time-of-flight between these reflections using the accepted speed of sound in the cornea of $1636-1640 \mathrm{~m} / \mathrm{sec} .{ }^{3}$ Variability in ultrasound pachymetry measurements is largely dependent on decentration, the oblique incidence of light, and compression of the cornea by the probe. ${ }^{9,14}$

The Artemis-2 (Artemis Medical Technologies Inc, BC, Canada) as described by the manufacturer is a high-frequency precision ultrasound device that uses a $20-60 \mathrm{mHz}$ transducer to scan the eye in an arc, the curvature of which approximates that of the anterior ocular surface. It enables wide angle pachymetry of the individual layers of the cornea continuously over the central $10 \mathrm{~mm}$ diameter of the cornea, ${ }^{20}$ with a central frequency of $38 \pm 2 \mathrm{mHz}$ and a scan repetition frequency of $2 \mathrm{~Hz}$. Measurements can also be made of the anatomic structures, including the anterior chamber depth, angle-to-angle width, and sulcus to-sulcus width. The instrument has an axial and lateral resolution of $35 \mu \mathrm{m}$, and $65 \mu \mathrm{m}$, respectively. In Artemis-2, the cornea is offset from the probe by being immersed in a normal saline medium. The probe is moved in an arc-shaped trajectory that is matched approximately to the corneal curvature, enabling near normal incidence at all positions during scanning. The device incorporates a fixation light for the patient and an optical camera for visualization of the patient's eye for the examiner to assure centration.

As reported by Bland and Altman, ${ }^{21}$ comparison of new measurement techniques with established ones in clinical measurement is often needed to assess whether the results of the two methods agree sufficiently for the new technique to replace the old. If the new method agrees sufficiently well with the old, then the two methods may be used interchangeably and the old may be replaced. In order to know the extent of agreement between the techniques, assessing their repeatabilities is important, because repeatability limits the amount of agreement between techniques. ${ }^{21}$

This study was undertaken to assess the repeatability and interobserver reproducibility of CCT measurements obtained using the high-frequency ultrasound system (Artemis-2), and also to compare the results with those of established 
CCT measurement techniques, ultrasound pachymetry, and noncontact specular microscope.

\section{Materials and methods}

This study adhered to the tenets of the Declaration of Helsinki and was approved by the college institutional review board of the university. Verbal informed consent was obtained from each participant after the study protocol had been clearly explained, and the study was carried out between October 2011 and February 2012. Thirty-two subjects (14 women and 18 men) of mean age $24 \pm 5$ (range 21-42) years, were randomly selected from students of different colleges of the university for a comprehensive ophthalmologic examination. This prospective study was conducted at the Department of Optometry outpatient clinic. Subjects had to be oculovisually healthy, with no history or observable signs of ocular surgery, corneal opacities, corneal edemas, corneal dystrophies, or active ocular surface disease. Subjects who had difficulty sitting through the measurements with any one of the pieces of equipment (usually with the Artemis-2) were also excluded. Contact lens wearers were required to discontinue lens wear 24 hours before the day of examination. Three subjects were lost to follow-up and one was excluded because of a corneal scar.

\section{Measurement techniques}

All measurements were taken between 11 am and $2 \mathrm{pm}$ in order to minimize the effects of diurnal variation in CCT. ${ }^{22}$ CCT measurements were first obtained with the SP-3000P, and subsequent measurements were randomized between the Artemis-2 and the DGH-500. This was due to the fact that the Artemis-2 scanner and DGH-500 measure CCT invasively, while the SP-3000P is noninvasive in its assessment. Randomization for both the selected eye of each patient and for the order of measurement with the ultrasound devices were carried out using a table of random numbers generated from an Microsoft Excel spread sheet. CCT measurements were repeated on a second visit approximately one week later to assess repeatability. There was no randomization during the second visit. The eye assessed for CCT was the same eye that was measured during the first visit and the order of measurement with the ultrasound devices was reversed from the order in session 1. During the first visit, the same examiner obtained CCT readings with the SP-3000P and the DGH-500, while the other examiner obtained the measurement with the Artemis-2. In session 2, the examiners were rotated. With all techniques, three average CCT measurements were recorded and used for further comparative analysis.

\section{Topcon SP-3000P noncontact specular microscopy}

For CCT measurements using the specular microscope, corneal images were captured with the chin on the chin rest, the head on the forehead rest, and the subject fixating the central target. The automatic image capture low intensity mode of the specular microscope was employed in this study to minimize examiner-dependent bias. Three average CCT measurements were recorded for each eye in each session, with each average comprising five CCT readings. A total of 15 CCT readings were taken for each eye per session using the automatic image capture mode.

\section{Artemis-2 high-frequency ultrasound}

The Artemis-2 system measurement was carried out as directed by the manufacturers, and also as described by Paul et al. ${ }^{3}$ With the subject seated, the chin and forehead appropriately positioned, the eye to be assessed was placed in a soft-rimmed eyecup. The subject fixated on a narrowly focused aiming beam, which was coaxial with the corneal apex through an aperture surrounded by a disposable viscoelastic transparent membrane. Subjects were then advised to position themselves so that they could achieve a good seal all around the eye. This prevented any leakage of saline. Normal sterile saline was then filled into the eyepiece to form an acoustic coupling medium between the eye and the transparent membrane. In this manner, the position of each scan plane was maintained about a single point on the cornea, and cornea mapping was therefore centered on the cornea vertex. The ultrasound transducer and scan mechanism were submerged in degassed water within the body of the scanner and separated from the eye by the transparent membrane. Behind the transducer was an optical system including a beam-splitter, a blinking fixation light, and a digital infrared camera. With the subject directing his or her gaze at the fixation light, the scan axis was centered by moving the scan mechanism with a joystick until the crosshair representing the ultrasound axis was centered within the pupil. When proper alignment was achieved, the range of the transducer to the cornea was adjusted to place the cornea in the acoustic focal plane. When alignments were complete, continuous B scans were acquired by the operator (measurements are valid in any direction). About ten B scans were obtained for each subject, while only three valid Artemis-2 scan images which conformed to the corneal arc shape in all directions were then analyzed with the Artemis-2 software. The software of the instrument was used to correct these images geometrically 
(measurements conforming to corneal arc shape in all directions) for each eye.

To obtain the cornea thickness values, a live measuring tool is displayed, in which the yellow line indicates the thickness of the position of interest (the thickness value is displayed in green color). CCT was then determined by placing the measuring tool on the central cornea. The value displayed was then recorded for each of the three selected scans and used for statistical analysis. The corneal sound velocity setting used for analysis of Artemis-2 data was $1636 \mathrm{~m} / \mathrm{sec}$.

\section{DGH-500 hand-held ultrasound pachymeter}

For ultrasound pachymetry measurements, the cornea was anesthetized with one drop of $1 \%$ tetracaine hydrochloride, while the ultrasound probe was disinfected with an alcohol swab before each subject. Subjects were seated while looking straight ahead and the probe was lightly placed perpendicularly to the central corneal surface taking care to avoid excessive compression of the probe tip against the cornea. The pupil center was used as reference for probe placement. The ultrasound velocity was set to $1640 \mathrm{~m} / \mathrm{sec}$ for all measurements, in accordance with the manufacturer's recommendation for calibration.

\section{Statistical analysis}

Graphpad Instat version 3.00 (Graphpad Software Inc, San Diego, CA) was used for the statistical analysis. Differences were considered significant at the $P<0.05$ level. In order to know the extent of agreement between the techniques, assessing their repeatabilities is important, because repeatability limits the amount of agreement between techniques. ${ }^{21}$ For repeatability of each technique, we assessed within-eye repeatability and the coefficient of repeatability in each session.

The standard deviation (SD) of three average measurements (in the Artemis-2, the three geometrically corrected measurements) in each subject were averaged. The average SD was then used to calculate the withineye repeatability $\left(1.96 * \mathrm{SD}^{\text {within subject standard deviations }}\right)$ in the population. $^{22}$ The coefficient of repeatability was calculated as $1.96 \times \mathrm{SD}^{\text {within-session mean differences }}{ }^{23}$ Interobserver reproducibility was also calculated as $1.96 * \mathrm{SD}^{\text {between-session mean differences }}$.

To estimate the agreement between sessions of the same method and between tested methods, repeated-measures analysis of variance, and the Bland-Altman ${ }^{24}$ method of analysis were conducted on the mean CCT values.
The six columns analyzed were ultrasound pachymetry session 1 and 2 versus Artemis session 1 and 2 versus SP-3000P sessions 1 and 2. Two limits of agreement

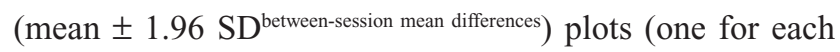
session) were combined on the same graph, for each pair of techniques.

To investigate whether the order of measurement affected CCT values obtained with either the Artemis-2 or the handheld ultrasound pachymeter, an unpaired Student's $t$-test was performed in both sessions to compare, for example, the ultrasound pachymetry CCT values returned when the ultrasound pachymetry was used to assess CCT before the Artemis-2 (13 eyes), with values returned when ultrasound pachymetry was used to assess CCT after the Artemis-2 (19 eyes).

\section{Results}

Pachymetry results obtained with the three different methods in session 1 and session 2 are summarized in the descriptive statistics shown in Table 1.

\section{Repeatability}

The within-eye repeatability of CCT measurements represented by the mean SD for session 1 and session 2, respectively, were: $\pm 5.2 \mu \mathrm{m}$ and $\pm 5.0 \mu \mathrm{m}$ for SP-3000P; $\pm 3.7 \mu \mathrm{m}$ and $\pm 3.4 \mu \mathrm{m}$ for Artemis-2; and $\pm 5.4 \mu \mathrm{m}$ and $\pm 5.6 \mu \mathrm{m}$ for DGH-500. Table 2 shows the results of the Bland-Altman analysis of the mean difference within sessions of each technique (average of first reading minus second reading, first reading minus third reading, second reading minus third reading) standard deviations, 95\% confidence intervals (mean $\pm 1.96 * \mathrm{SD}$ of mean differences) together with their coefficients of repeatability. There was no statistically significant difference (repeated-measures analysis of variance, $P>0.05$ ) between sessions for the three pachymetry

Table I Mean central corneal thickness taken with Topcon SP-3000P noncontact specular microscope, ultrasound pachymeter DGH-500, and Artemis-2 very high-frequency ultrasound

\begin{tabular}{lllll}
\hline Device & $\begin{array}{l}\text { Mean CCT } \mu \mathrm{m} \\
( \pm \text { SD) }\end{array}$ & Minimum & Maximum & $\begin{array}{l}95 \% \mathrm{Cl} \\
\text { of mean }\end{array}$ \\
\hline $\begin{array}{l}\text { Session I } \\
\text { SP-3000P }\end{array}$ & $520 \pm 29$ & 466 & 567 & $509-530$ \\
DGH-500 & $560 \pm 33$ & 507 & 613 & $548-571$ \\
Artemis-2 & $558 \pm 33$ & 502 & 619 & $546-569$ \\
Session 2 & & & & \\
SP-3000P & $520 \pm 30$ & 453 & 572 & $508-531$ \\
USP & $561 \pm 37$ & 486 & 621 & $548-574$ \\
Artemis-2 & $554 \pm 34$ & 506 & 616 & $542-566$ \\
\hline
\end{tabular}

Abbreviations: CCT, central corneal thickness; $\mathrm{Cl}$, confidence interval; SD, standard deviation; USP, ultrasound pachymeter. 
Table 2 Bland and Altman analysis of central corneal thickness measurements obtained by SP-3000P, Artemis-2, and DGH-500 ultrasound pachymetry

\begin{tabular}{llllll}
\hline Techniques & $\begin{array}{l}\text { Mean } \\
\text { difference } \\
(\mu \mathrm{m})\end{array}$ & SD & $\begin{array}{l}\mathbf{9 5 \%} \mathbf{C l} \\
(\mu \mathrm{m})\end{array}$ & $\boldsymbol{P}$ value & CoR \\
\hline SP-3000P $^{\mathrm{a}}$ & -0.9 & 4.7 & -10.0 to 8.2 & $>0.05$ & \pm 9.1 \\
SP-3000P $^{\mathrm{b}}$ & -0.9 & 5.5 & -11.6 to 9.9 & & \pm 10.8 \\
Artemis-2 $^{\mathrm{a}}$ & -0.5 & 4.1 & -8.6 to 7.6 & $>0.05$ & \pm 8.1 \\
Artemis-2 $^{\mathrm{b}}$ & -0.9 & 4.6 & -9.9 to 8.1 & & \pm 9.0 \\
DGH-500 $^{\mathrm{a}}$ & 0.6 & 6.3 & -11.8 to 13.0 & $>0.05$ & \pm 12.4 \\
DGH-500 $^{\mathrm{b}}$ & -1.7 & 6.2 & -13.9 to 10.4 & & \pm 12.1 \\
\hline
\end{tabular}

Notes: Mean difference within session, standard deviations, $95 \%$ confidence intervals (mean $\pm 1.96 \mathrm{SD}$ ) in each technique with their $C o R^{*}$ are represented. $P$ value is

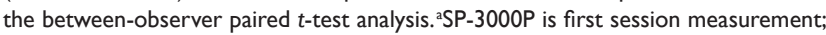
bSP-3000P is second session measurement; *statistically significant at the 0.05 .

Abbreviations: $\mathrm{Cl}$, confidence interval; CoR, coefficients of repeatability; $\mathrm{SD}$, standard deviation.

devices; the Artemis- 2 was the most repeatable, followed by SP-3000P and DGH-500.

Table 2 shows that there was no statistically significant difference between average CCT measurements obtained by different observers (session 1 and session 2). However, the SP-3000P showed the smallest magnitude of the individual differences of means, followed by the DGH-500 and the Artemis-2. Between observers, the difference for the SP-3000P, Artemis-2, and DGH-500, respectively, were $0.1 \mu \mathrm{m}(95 \%$ confidence interval $[\mathrm{CI}]-16.9$ to 16.7), $3.6 \mu \mathrm{m}$ (95\% CI -27.5 to 34.7$)$, and $-1.5 \mu \mathrm{m}$ ( $95 \%$ CI -30.2 to 27.2). The coefficient of reproducibility was superior for SP-3000P $( \pm 17 \mu \mathrm{m})$ but similar for the Artemis-2 $( \pm 31 \mu \mathrm{m})$ and DGH-500 $( \pm 29 \mu \mathrm{m})$.

\section{Comparison of CCT measurements obtained by the three methods}

There were statistically significant differences between the CCT measurements returned by the three methods in session 1 (repeated-measures analysis of variance, $P<0.0001$ ) and in session 2 (repeated-measures analysis of variance, $P<0.0001$ ).

Figure 1 is a limits of agreement plot of the mean difference between CCT measurements obtained by the Artemis- 2 and the SP-3000P for both sessions. The Artemis-2 measurement was significantly larger than that measured using the SP-3000P by an average of $38 \mu \mathrm{m}$ and $34 \mu \mathrm{m}$ for session 1 and session 2, respectively, but similar to that of the DGH-500 in both sessions (Figure 2).

As shown in Figure 3, the DGH-500 corneal thickness values were significantly higher $(P<0.001)$ than those measured with the SP-3000P in session $1(40 \mu \mathrm{m})$ and session $2(41 \mu \mathrm{m})$. The limits of agreement plots are also shown in Figure 3.

In both sessions, the limit of agreement between the techniques as shown in the Bland and Altman plots was consistently narrower for the DGH-500 versus Artemis-2 comparison, followed by the Artemis-2 versus SP-3000P comparison, then the DGH-500 versus SP-3000P comparison.

Overall, in 19 eyes, CCT was first measured with the Artemis-2 while in the other 13 eyes it was first measured with the DGH-500. In both sessions, prior use of the Artemis-2 did not significantly alter the corneal thickness measured subsequently with the DGH-500, nor did prior use of DGH-500 significantly alter CCT measured subsequently with the Artemis-2 $(P>0.05)$.

Comparison of the average time taken to align and obtain measurements in one eye of each patient with the three devices showed that measurement of CCT by the Artemis-2 took the longest time (between 10 and 15 minutes, excluding time taken to enter patient data in the system software). Measurements by the SP-3000P were obtained in as little as one minute while the DGH-500 took about 6 minutes, including instillation of anesthetic.

\section{Discussion}

One of the most important factors for patient selection in corneal refractive surgery is CCT. Currently, devices used in the assessment of corneal thickness can often be used for biometric measurement in cataract surgery, such as measurement of anterior chamber depth, lens thickness, and axial length, for selection of appropriate intraocular lens power. ${ }^{25}$ Comparison of the new measurement techniques with established ones is often needed to see whether the results for the new methods agree sufficiently to be used interchangeably. ${ }^{26}$ The ultrasound pachymeter (DGH-500) is the most commonly used technique, and is considered the gold standard for the assessment of CCT. Previous studies have demonstrated that the DGH-500 produces consistently higher CCT values when compared with other techniques in normal ${ }^{14,26-30}$ and abnormal corneas. ${ }^{10,30}$ Ultrasound pachymetry has been reported to measure significantly higher CCT values in relation to the noncontact specular microscope in normal subjects ${ }^{14,27,31}$ but not in post-LASIK subjects. ${ }^{1,12,31}$ CCT values were overestimated in the normal corneas by about $32 \mu \mathrm{m},{ }^{14} 28 \mu \mathrm{m},{ }^{27} 27 \mu \mathrm{m},{ }^{31} 26 \mu \mathrm{m},{ }^{29}$ and about $19 \mu \mathrm{m}^{30}$ in post-LASIK corneas, in relation to the noncontact specular microscope. The results of this study are consistent 


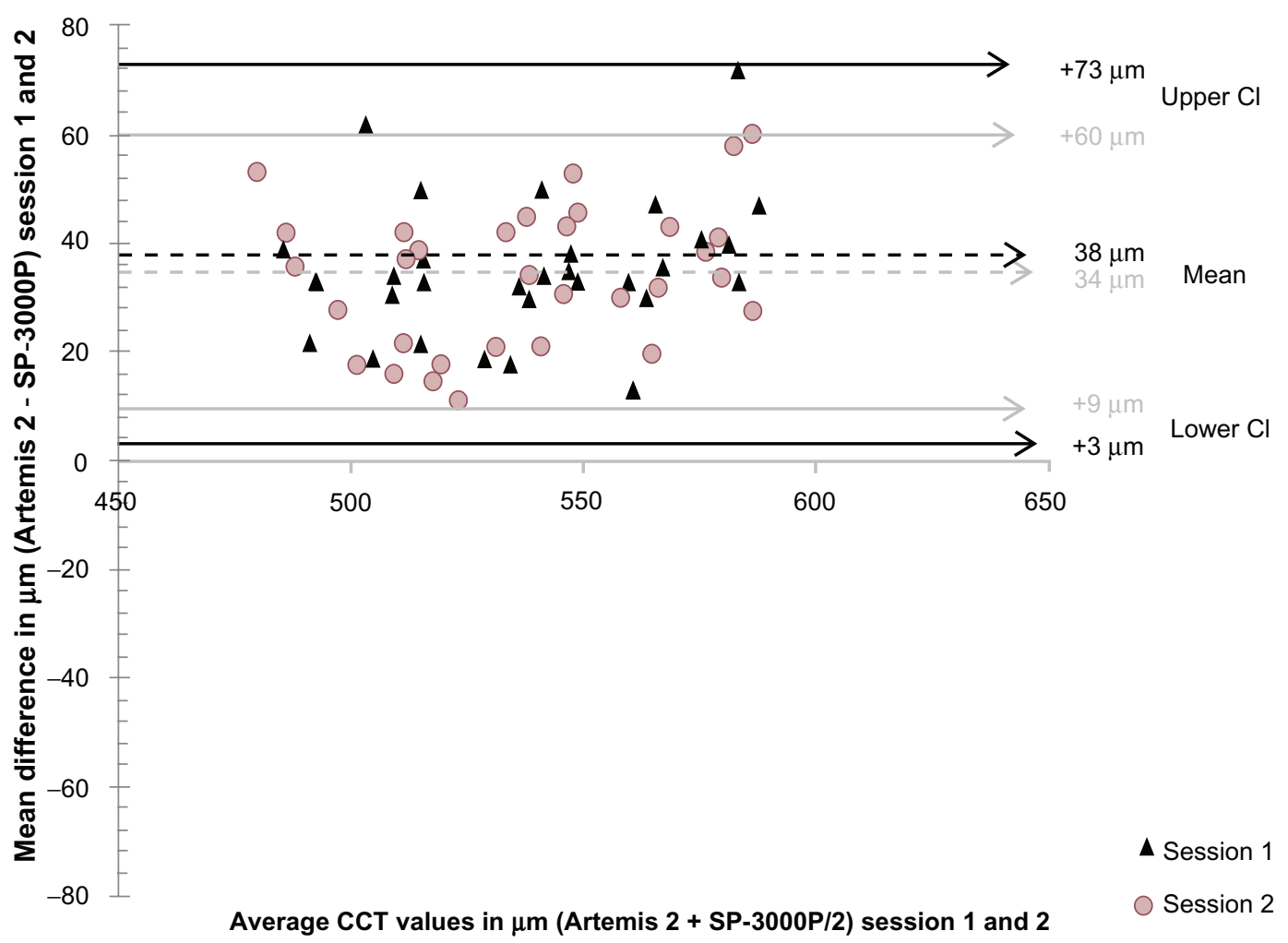

Figure I Bland-Altman plot of mean difference in central corneal thickness measurements between Artemis-2 and SP-3000P noncontact specular microscope against their mean in session I and session 2 .

Notes: Mean difference in session I, $P<0.001$; session 2, $P<0.001$.

Abbreviations: $\mathrm{CCT}$, central corneal thickness; $\mathrm{Cl}$, confidence interval.

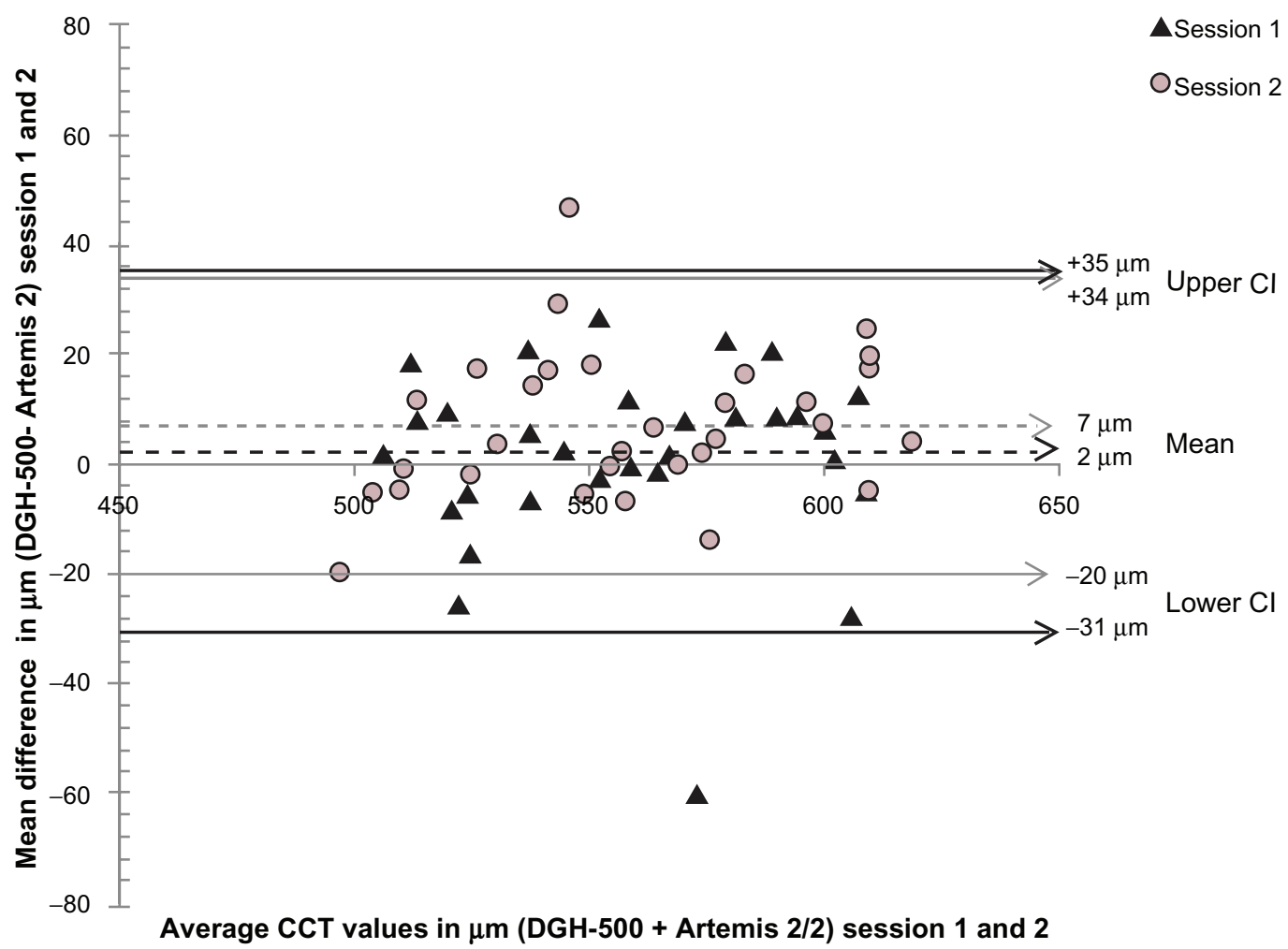

Figure 2 Bland-Altman plot of mean difference in central corneal thickness measurements between ultrasound pachymetry and Artemis-2 against their mean in session I and session 2 .

Notes: Mean difference in session I, $P>0.05$; session 2, $P>0.05$

Abbreviations: $\mathrm{CCT}$, central corneal thickness; $\mathrm{Cl}$, confidence interval. 


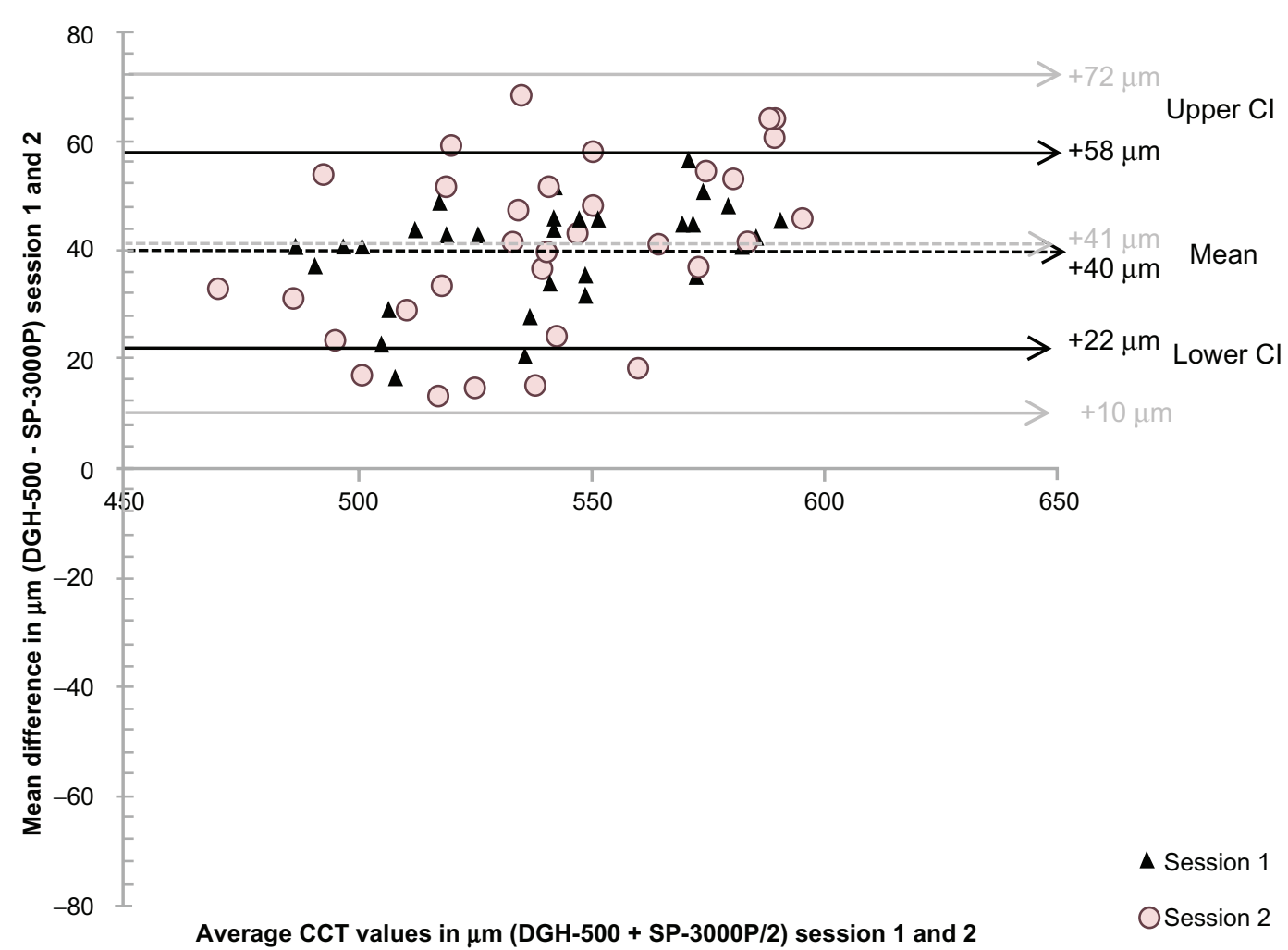

Figure 3 Bland-Altman plot of mean difference in central corneal thickness measurements between ultrasound pachymetry and SP-3000P noncontact specular microscope against their mean in session I and session 2 .

Notes: Mean difference in session I, $P<0.00$ I; session 2, $P<0.00$ I.

Abbreviations: $\mathrm{CCT}$, central corneal thickness; $\mathrm{Cl}$, confidence interval.

with these findings. In both sessions, both ultrasound devices (Artemis-2 and DGH-500) caused overestimation of corneal thickness values and therefore a relative underestimation for SP-3000P. The difference between the SP-3000P pachymetry values and the two ultrasound devices used in our study is most likely the result of different operating principles. The noncontact specular microscopy is dependent on the reflection of light, and the DGH-500 depends on the reflection of ultrasonic waves from the anterior and posterior corneal surfaces. The exact posterior reflection point is not known in DGH-500, but it may be located between the Descement membrane and the anterior chamber. If the reflection point is located at the anterior chamber, this will cause overestimation of the corneal thickness. ${ }^{14}$

Measurements of CCT taken with the DGH-500 and the Artemis-2 were in agreement because no significant difference was returned for both these ultrasonic devices. In an earlier study ${ }^{3}$ comparing Artemis-2 CCT measurements with those of a hand-held ultrasound pachymeter, the Artemis-2 measured significant thinner $(11 \mu \mathrm{m})$ CCT values when compared with ultrasound pachymetry in normal subjects. This could be due to the fact that our sample was more homogeneous considering the ages of the subjects and, as such, less prone to variations. With the exception of the DGH-500, the within-subject repeatability of CCT measurements found in the present study in both sessions $(3.7 \mu \mathrm{m}$ and $3.4 \mu \mathrm{m}$ for the Artemis-2; $5.1 \mu \mathrm{m}$ and $5.0 \mu \mathrm{m}$ for the SP$3000 \mathrm{P}$ ) was within the range of $3-5 \mu \mathrm{m}$ repeatability reported for CCT measurements obtained in a standard clinical setting with the patient in a sitting position. ${ }^{32}$ This suggests that within-subject repeatability was best with the Artemis- 2 and worst with the DGH-500. The main sources of error affecting the repeatability of ultrasound pachymetry include placement of the probe, maintaining its perpendicularity on the cornea, and compression of the cornea by the probe. The Artemis- 2 is largely unaffected by these factors because the cornea is offset from the probe by a normal saline immersion medium while the scanning is done.

The interobserver coefficient of reproducibility (between sessions) with the two ultrasonic devices was almost twice that with the SP-3000P, showing that CCT measurements obtained by the SP-3000P were the most interobserver-reproducible, possibly because of smaller operator-dependent biases with the positioning of the patient and/or the device. In a comparative study by Modis et $\mathrm{al}^{27}$ assessing the CCT of normal white adults, a slightly inferior repeatability coefficient of $12.6 \mu \mathrm{m}$ 
and $17.9 \mu \mathrm{m}$ (first and second investigator, respectively) with respect to our observation $(12.4 \mu \mathrm{m}$ and $12.1 \mu \mathrm{m}$, for the first and second session, respectively) was reported for ultrasound pachymetry. In the present study, the second examiner obtained higher thickness values using ultrasound pachymetry, which further reaffirms that CCT measurements obtained using ultrasound pachymetry are observer-dependent. ${ }^{11}$ Its accuracy is dependent on placement of the probe perpendicular to the cornea, in the same spot from one measurement to the next. A few authors have also reported similar variability in CCT values obtained between observers with ultrasound pachymetry in healthy ${ }^{33}$ and keratoconic eyes. ${ }^{34}$

Although excellent repeatability was established for the three tested devices, there were significant differences between the SP-3000P and the two ultrasonic devices in determination of CCT in young normal subjects. Further studies are needed to verify this relationship in larger samples of normal subjects and in subjects with raised intraocular pressure, and also to establish a possible correction factor for SP-3000P because it consistently measures CCT values lower than the popularly used measurement techniques. Increasing the number of subjects will enhance the statistical power of the present study.

Generally, SP-3000P may be preferred for routine measurement and monitoring of CCT in older patients and children because obtaining CCT measurement by SP-3000P is rapid, easy, requires no expertise or topical anesthetic, and is noninvasive. However, in comparison with the Artemis-2, the DGH-500 is less invasive, easy to use, requires little space, and measurements are obtained in a shorter time. In contrast, it is unlikely that the Artemis will be commonly used in routine CCT measurements because it is more invasive, takes a longer time to obtain CCT measurements in a patient, it is difficult to have patients immerse their eye in the eye cup filled with saline and maintain fixation, is more expensive, is bulky, and requires a much larger space, and most importantly needs constant maintenance and calibration. Also, using the Artemis-2 requires adequate training and expertise and, as such, CCT measurements by Artemis-2 cannot be delegated to nonprofessionals. Measurements in children may be very difficult or impossible. However, the Artemis-2 may play an important role in research laboratories for the purposes of collecting data and comparison, and also during planning and monitoring of refractive surgeries.

In conclusion, CCT measurements with the Artemis-2 high-frequency ultrasound device are comparable with those measured with DGH-500, but neither ultrasonic device gave CCT readings comparable with those measured with the
SP-3000P. Repeatability was good for the three techniques, but best with the Artemis-2. However, interobserver reproducibility was best for the SP-3000P, with each of the reproducibility coefficients for the DGH-500 and Artemis-2 almost double that of the SP-3000P. Therefore, when recording CCT for the purpose of planning a surgery (or for post-surgical CCT monitoring), the CCT readings from the ultrasound devices assessed here may be used interchangeably, but neither can be used interchangeably with the SP-3000P noncontact specular microscope.

\section{Disclosure}

The authors do not have any commercial or proprietary interest in any product or company mentioned in this work.

\section{References}

1. Zhao MH, Zou J, Wang WQ, Li J. Comparison of central corneal thickness as measured by non-contact specular microscopy and ultrasound pachymetry before and post LASIK. Clin Experiment Ophthalmol. 2007;35:818-823

2. Konstantopoulos A, Hossain P, Anderson DF. Recent advances in ophthalmic anterior segment imaging: a new era for ophthalmic diagnosis. Br J Ophthalmol. 2007;91:551-557.

3. Paul T, Lim M, Starr CE, Lloyd HO, Coleman DJ, Silverman RH. Central corneal thickness as measured by Orbscan II, ultrasound pachymeter and Artemis-2. J Cataract Refract Surg. 2008;34:1906-1912.

4. Ou RJ, Shaw EL, Glasgow BJ. Keratectasia after laser in situ keratomileusis (LASIK): evaluation of the calculated residual stromal bed thickness. Am J Ophthalmol. 2002;134:771-773.

5. Kwon RO, Price MO, Price FW Jr, Ambrósio R Jr, Belin MW. Pentacam characterization of corneas with Fuch dystrophy treated with Descement membrane endothelial keratoplasty. J Cataract Refract Surg. 2010;26:972-979.

6. Martin R, de Juan V, Rodríguez G, Cuadrado R, Fernandez I. Measurement of corneal swelling variations without removal of the contact lens during extended wear. Invest Ophthalmol Vis Sci. 2007;48:3043-3050.

7. Gordon MO, Beiser JA, Brandt JD, et al. The Ocular Hypertension Treatment Study: baseline factors that predict the onset of primary open angle glaucoma. Arch Ophthalmol. 2002;120:714-720.

8. Whictacre MM, Stein RA. Sources of error with the use of Goldmann type tonometers. Surv Ophthalmol. 1993;38:1-30.

9. Korah S, Thomas R, Muliyil J. Comparison of optical and ultrasound pachymetry. Indian J Ophthalmol. 2000;48:279-283.

10. Francisco L, Fernández-Sánchez V, López-Gil N, Cerviño A, Montés-Micó R. Comparison of partial coherence interferometry and ultrasound for anterior segment biometry. J Cataract Refract Surg. 2009;35:324-329.

11. Marsich MW, Bullimore M. Repeatability of corneal thickness measures. Cornea. 2000;19:792-795.

12. Kawana K, Miyata K, Tokunaga T, Kiuchi T, Hiraoka T, Oshika T. Central corneal thickness measurements using Orbscan II scanning slit topography, noncontact specular microscopy, and ultrasonic pachymetry in eyes with keratoconus. Cornea. 2005;24:967-971.

13. Avitabile T, Franco L, Ortisi E, et al. Keratoconus staging: a computerassisted ultra biomicroscopic method compared with videokeratographic analysis. Cornea. 2004;23:655-660.

14. Bovelle R, Kaufman SC, Thompson HW, Hamano H. Corneal thickness measurements with the Topcon SP-2000P specular microscope and an ultrasound pachymeter. Arch Ophthalmol. 1999;117:868-870. 
15. Liu Z, Huang AJ, Pflugfelder SC. Evaluation of corneal thickness and topography in normal eyes using the Orbscan corneal topography system. Br J Ophthalmol. 1999;83:774-778.

16. Rainer G, Petternel V, Findl O, et al. Comparison of ultrasound pachymetry and partial coherence interferometry in the measurement of central corneal thickness. J Cataract Refract Surg. 2002;28:2142-2145.

17. Reinstein DZ, Archer TJ, Gobbe M, Silverman RH, Coleman DJ. Repeatability of layered corneal pachymetry with the Artemis very high-frequency digital ultrasound arc scanner. J Refract Surg. 2010;26:646-659.

18. O'Donnell C, Maldonado-Codina C. Agreement and repeatability of central thickness measurement in normal corneas using ultrasound pachymetry and the Oculus Pentacam. Cornea. 2005;24:920-924.

19. Ceylan OM, Turk A, Erdurman C, et al. Comparison of Oculus Pentacam and Stratus optical coherence tomography for measurement of central corneal thickness. Cornea. 2011;30:670-674.

20. Reinstein DZ, Archer TJ, Silverman RH, Coleman DJ. Accuracy, repeatability, and reproducibility of Artemis very high-frequency digital ultrasound arc-scan lateral dimension measurements. J Cataract Refract Surg. 2006;32:1799-1802.

21. Bland JM, Altman DG. Measurement error. BMJ. 1996;313:744.

22. Lattimore MR Jr, Kaupp S, Schallhorn S, Lewis R IV. Orbscan pachymetry: implications of a repeated measures and diurnal variation analysis. Ophthalmology. 1999;106:977-981.

23. British Standards Institution. Precision of Test Methods 1: Guide for the Determination and Reproducibility for a Standard Test Method (BS 597, Part 1). London, UK: British Standards Institution; 1975.

24. Bland JM, Altman DG. Agreement between methods of measurement with multiple observations per individual. J Biopharm Stat. 2007; 17:571-582.

25. Bjeloš Rončević M, Bušić M, Cima I, Kuzmanović Elabjer B, Bosnar D, Miletić D. Intraobserver and interobserver repeatability of ocular components measurement in cataract eyes using a new optical low coherence reflectometer. Graefes Arch Clin Exp Ophthalmol. 2011;249:83-87.
26. Ogbuehi KC, Almubrad TM. Repeatability of central corneal thickness measurements measured with the Topcon SP-2000P specular microscope. Graefes Arch Clin Exp Ophthalmol. 2005;243:798-802.

27. Módis L Jr, Langenbucher A, Seitz B. Corneal thickness measurements with contact and noncontact specular microscopic and ultrasonic pachymetry. Am J Ophthalmol. 2001;132:517-521.

28. Suzuki S, Oshika T, Oki K, et al. Corneal thickness measurements: scanning slit corneal topography and noncontact specular microscope versus ultrasonic pachymetry. J Cataract Refract Surg. 2003;29:1313-1318.

29. González-Pérez J, González-Méijiome JM, Ares MTR, Parafita MÁ. Central corneal thickness measured with three optical devices and ultrasound pachometry. Eye Contact Lens. 2011;37:66-70.

30. Al-Aqeel S, Al-Muammar AM. Comparison of central corneal thickness measurements by Pentacam, noncontact specular microscope, and ultrasound pachymetry in normal and post-LASIK eyes. Saudi J Ophthalmol. 2009;23:181-187.

31. Kawana K, Tokunaga T, Miyata K, Okamoto F, Kiuchi T, Oshika T. Comparison of corneal thickness measurements using Orbscan II, noncontact specular microscopy, and ultrasonic pachymetry in eyes after laser in situ keratomileusis. Br J Ophthalmol. 2004;88:466-468.

32. Reinstein DZ, Archer MA, Gobbe M. Repeatability of intraoperative central corneal and residual stromal thickness measurement using a handheld ultrasound pachymeter. J Cataract Refract Surg. 2012;38:278-282.

33. Lackner B, Schmidinger G, Pieh S, Funovics MA, Skorpik C. Repeatability and reproducibility of central corneal thickness measurement with Pentacam, Orbscan, and ultrasound. Optom Vis Sci. 2005;82:892-899.

34. de Sanctis U, Missolungi A, Mutani B, Richiardi L, Grignolo FM. Reproducibility and repeatability of central corneal thickness measurement in keratoconus using the rotating Scheimpflug camera and ultrasound pachymetry. Am J Ophthalmol. 2007;144:712-718.
Clinical Ophthalmology

\section{Publish your work in this journal}

Clinical Ophthalmology is an international, peer-reviewed journal covering all subspecialties within ophthalmology. Key topics include: Optometry; Visual science; Pharmacology and drug therapy in eye diseases; Basic Sciences; Primary and Secondary eye care; Patient Safety and Quality of Care Improvements. This journal is indexed on

\section{Dovepress}

PubMed Central and CAS, and is the official journal of The Society of Clinical Ophthalmology (SCO). The manuscript management system is completely online and includes a very quick and fair peer-review system, which is all easy to use. Visit http://www.dovepress.com/ testimonials.php to read real quotes from published authors. 